\title{
CITIZEN SCIENCE:
}

\author{
Co-constructing access, interaction, and participation
}

by Per Hetland

How do civic educators and citizen communities co-construct access, interaction, and participation and bridge contributory and democratized citizen science? This study builds on interviews and observations with amateur naturalists, professional biologists, and public authorities about their participation in the Species Observations System (SO)-Norway's largest citizen science (CS) project.

Over more than twenty years, CS has been understood as either contributory (contributing with data) or democratized (emancipating the pursuit of science). Following these models, CS studies has developed a number of classifications of CS projects. The present article aims to bridge contributory CS and democratized CS by using the access, interaction, and participation (AIP) model outlined by Carpentier, without extending the number of classifications.

Access and interaction signify contributory CS. Well-functioning technology is a precondition for joining the ranks of records, contributors, validators, and institutional actors. Interaction is the second founding stone of participation, and organizations are crucial to facilitating interaction. Participation signifies democratized CS. The choice of technology involves important dimensions of power, as technology structures actions. However, the ability to build and sustain the technological infrastructure also illustrates that participation is organizational power, enacted both from the bottom-up and top-down.

Keywords: Author: Licensing: 


\section{Introduction}

Over the last twenty years, CS has been understood as either contributory (contributing with data) (Bonney, 1996) or democratized (emancipating the pursuit of science) (Irwin, 1995). Recently, there have been several attempts to bridge the two approaches (Cavalier \& Kennedy, 2016; Ceccaroni \& Brenton, 2017; Hecker et al., 2018; Hetland, 2020; Shirk et al., 2012; Woolley et al., 2016). However, several of the attempts have only partially managed to include democratized CS. Studying Norway's largest CS project, this article aims to use the AIP (access, interaction, participation) model (Carpentier, 2012, 2015) to study how we may build bridges between contributory and democratized CS. Carpentier understands access as presence, for example in an organizational structure or a community, interaction emphasizes the social-communicative relationships that are established with other humans or objects, and participation is defined by power relations in decision-making processes. Consequently, participation is something more than the rather loosely defined concept in everyday language. Even if most participants only contribute with data and are less interested in becoming involved in other roles, participation is crucial to how we study CS's ability to facilitate co-deciding-either by personal involvement or by representatives. Only by including power in the study of CS will one be able to study CS as "a form of science developed and enacted by citizens themselves" (Irwin, 1995, p. xi).

The term "CS" is used here to refer to public participation in scientifically founded knowledge production. The participants in the study are referred to as either amateur naturalists, professional scientists, or public authorities. The study also emphasizes that, primarily, the activity is mutually beneficial to both the amateur naturalist, professional scientist and public authorities. The amateur naturalist benefits from taking part in large projects that contextualize individual and local activities and provide added value for participants-either through objects such as private diaries, ranking lists, and maps or, more generally, through partaking in knowledge production-while professional scientist and public authorities benefit by mobilizing a large crowd of contributors (Hetland, 2020). What distinguishes the participants is that the first group (i.e., amateur naturalists) conduct their activities mostly without pay and often as a hobby, while the members of the second group (i.e., professional scientists and public authorities) conduct their activities as part of their paid occupation. The concept "amateur" has its roots in Latin (amator-lover) and is here used for persons practicing an activity without having this as a livelihood, even if some are highly skilled and hold science degrees. Science communication is a core activity of organized science, and earlier studies have identified four major constructions of publics: the general public, the pure public, the affected public, and the partisan public (Hetland, 2019). Amateur naturalists are part of the affected publics, while public authorities are part of partisan publics. In this case study, public authorities are a crucial group running the technological infrastructure and the activities necessary to maintain the quality of its content (Bowker, 2000; Bowker \& Star, 1999; Karasti et al., 2016a, 2016b). Within both amateur naturalists, professional biologists, and public authorities one finds individuals that take on the role as civic educators, either as advocates or experts or both (Ceccaroni et al., 2017).

\section{Background of the case}

The Species Observation System (SO)' provided a new opportunity for amateur communities to participate in national biodiversity mapping activity and expedited new ways of bridging activities between science and the public. The Norwegian Biodiversity Information Centre (NBIC) was established in 2005 as a public service biological diversity bank, and it provides a number of services such as the Red List, the Alien Species List, the Species Names, the Species Map Service, and the SO. It also offers internet services including taxonomy, identification keys, and ecological data to describe the species, as well as a national typification and description system for the ecosystems, habitats, and ecological variations of the different kinds of Norwegian environments.
Furthermore, the NBIC began the Norwegian Taxonomy Initiative in 2009 to focus on generating new knowledge about poorly known species-groups in Norway. These services use a body of standards called the Darwin Core. ${ }^{2}$

The Norwegian Biodiversity Network (Sabima) ${ }^{3}$ was formed when nine non-governmental organizations (NGOs) organized themselves to lobby for improvements in environmental policies and the education of their members. With more than 19,000 members, these NGOs embrace both the professionals and the most skilled amateur naturalists in Norway. The NGOs aimed for a mutual database for both amateur naturalists, scientists, and

\footnotetext{
1 For more information on the Norwegian Biodiversity Information Centre, see https://www.biodiversity.no/Pages/135580

2 For more information on the Darwin Core, see http://rs.tdwg.org/dwcl

3 https://www.sabima.no
} 
public authorities. However, they were not completely satisfied with the registration system chosen by scientists; therefore, they argued that the NBIC should copy the very successful Swedish Artportalen. Artportalen is fairly easy to use, but it does not cater to all the needs of the scientists. In 2007, the Minister of the Environment, Helen Bjørnøy, decided to implement a solution that should increase public participation in biodiversity mapping. The new service was launched in May 2008. Sabima, together with five amateur organizations (the Norwegian Ornithological Society, the Norwegian Botanical Association, the Norwegian Foraging and Mycology Society, the Norwegian Zoological Society, and the Norwegian Entomological Society), are collaborating partners with the SO. Consequently, and building on the Artportalen, the SO tries to combine "top-down" and "bottom-up" approaches. The NBIC is responsible for running the SO on an everyday basis and has organized validation with the help of national coordinators and several interactive services. Furthermore, the establishment of the Global Biodiversity Information Facility (GBIF) connects Norwegian records with an increasing number of international records. ${ }^{4}$

As of September 2020, the SO has more than 12,000 contributors and about 24 million records and generally increases by more than 5,000 records every day. As one of the services linked to the SO, the Species Map Service is composed of species occurrence data collected on the same map interface and provides access to about 34 million Norwegian records, including a number of datasets from different scientific institutions. ${ }^{5}$ Consequently, more than two thirds of the records comes from SO. The so builds on the following general principles: ${ }^{6}$
- Everyone may contribute, regardless of their skills.

- Some records are always validated, such as the ones found on the Red List (threatened species) and the Alien Species List (invasive species).

- In general, all records are open. However, for some vulnerable species, there are different ways of hiding some of the recorded information. The main idea is that openness in itself leads to protection.

- Validation is partly organized by the NBIC, and partly by amateur naturalists themselves. Sabima recruits volunteers to validate species of national observation interest. Roughly 100 volunteers participate in the validation of birds, while 60 participate in the validation of the remaining species. They are comprised of both skilled amateur naturalists and professional biologists.

- The SO has an environmental and political impact through such services as the Species Map Service, the Red List, and the Alien Species List.

The primary aim of this article is theoretical by examining how to bridge contributory CS and democratized CS by studying the case of the SO. The case study seeks to answer one question through an examination of the emerging actors, processes, and institutions: How do civic educators and citizen communities in a large CS project co-construct access, interaction, and participation and bridge contributory and democratized CS? My claim is that one needs to facilitate a better understanding of participation within CS. Consequently, the AIP model will be an important tool in this respect.

\section{Theory}

Engagement and participation are central themes in science communication studies (Rowe \& Frewer, 2005), as well as in CS studies. A number of sub-models of CS are identified in the literature (Ceccaroni, Bowser, \& Brenton, 2017; Shirk et al., 2012). Three classification schemes organized around different features are often referred to: a) the nature of the activities participants engage in (Bonney et al., 2016), b) the extent to which different publics participate in parts of the scientific process (Shirk et al., 2012), and c) the level of participation between professional scientists and amateurs (Hakley, 2013). Consequently, there are a number of different definitions of CS. Ceccaroni et al. (2017) provide one definition that aims to bridge contributory and democratized CS:

Citizen science is work undertaken by civic educators together with citizen communities to advance science, foster a broad scientific mentality, and/or encourage democratic engagement, which allows society to deal rationally with complex modern problems. (p. 10)

Shared technological infrastructure also fosters shared ontological commitments that distinguish the participants as a broad citizenscience community of practice (Ceccaroni et al., 2017). Two earlier studies have mapped the participatory turn in CS research as well as a growing number of more complex typologies identifying this turn (Hetland, 2017; Hetland \& Schrøder, 2020). Consequently, this article's claim is that CS studies needs a simple but powerful analytical model that can accommodate both flexibility and a growing complexity without extending the number of models and typologies ad infinitum.

The three concepts-access, interaction and participation-have developed into important concepts describing how and which spaces citizens access, how citizens interact with each other socially

\footnotetext{
4 https://www.gbif.org

5 https://artskart.artsdatabanken.no/

6 Sourced from https://www.artsobservasjoner.no/Home/Fundamentals
} 
and communicatively, and how we think about participation (Carpentier, 2012, 2015). Carpentier claims that "access becomes articulated as presence, in a variety of ways that are related to four areas: technology, content, people and organizations" (2012, p. 173), while interaction "has a long history in sociological theory, where it often refers to the establishment of socio-communicative relationships" (2012, p. 174). Finally, the "difference between participation on the one hand, and access and interaction on the other is located within the key role that is attributed to power, and to equal(ized) power relations in decision-making processes" (2012, p. 174). In the final discussion, we will use Carpentier's AIP model $(2012,2015)$ to explore the bridge-building between contributory CS and democratized CS.

The different meanings attributed to access, interaction, and participation is structured on the basis of the four areas of their application. Access is articulated as the presence of first production technology, here exemplified by illustration from the SO: a) machines to produce and distribute content (the so portal), b) the presence of previously produced content (the SO archives), c) the presence of people to co-create (amateur naturalists, professional biologist, and public authorities), and, not the least, d) organizations such as amateur societies and their collaborative partners. The activities of amateur naturalists have a long history in the field of natural sciences (Conniff, 2011; Harris, Wyatt, \& Kelly, 2013; Jardine, Secord, \& Spary, 1996; Secord, 1994; Kohler, 2002, 2006). The motivations of participants for engaging in CS activities are widely studied (West \& Pateman, 2016), as they are often perceived to be acting for the benefit of others. Motivation to participate varies; Batson, Ahmed, and Tsang (2002) identify four categories of motives in general: egoism, altruism, collectivism, and principalism.

Egoism relates to motives that pertain to one's own welfare. Altruistic motives are related to increasing the welfare of others. Collectivism refers to increasing the welfare of a group. Principalism includes motives related to upholding a moral principle (e.g. justice, equality, caring for the environment). (Land-Zandstra et al., 2016, p. 47)

Reviewing previous research investigating motivation in CS, Jennett et al. (2014) find that motivations include interest in the research topic, learning new information, contributing to original research, enjoying the research task, sharing the same goals and values as the project, helping others and feeling part of a team, and finally, receiving recognition and feedback. However, the perspective provided on motivation in this article is somewhat different, as it is approached as a quest for reciprocity or a form of gift exchange (Carrier, 1991; Harris, Wyatt, \& Kelly, 2013; Mauss, 1950/2002; Sahlins, 1972, Sherry, 1983; Hetland, 2020). Reciprocity highlights a crucial element of CS: a personal relevance for different publics participating in CS (Frewer et al., 1999). Mauss (1950/2002, p. 50) describes three crucial obligations in a gift economy: "to give, to receive, to reciprocate."
Sahlins' typology of reciprocity includes generalized reciprocity (i.e., altruistic transactions), balanced or symmetrical reciprocity (i.e., the direct exchange of customary equivalents), and negative reciprocity (i.e., to get something for nothing) (Sahlins, 1972). A comfortable and respectful atmosphere is important in facilitating opportunities for reciprocity (Kramer \& Wells 2005).

Interaction describe socio-communicative relationships: a) using the SO to produce content in a prioritized manner, b) producing new content, c) co-producing as a group or community giving priority to certain tasks, and, d) co-producing meta-content in an organizational context. At the same time, it is important to remember that unstructured CS databases (i.e., records collected in an arbitrary manner) can be problematic when used for research purposes; e.g., they contain different forms of biases. These biases might lead to important long-term population declines (or increases) not being detected (Kamp et al., 2016). However, more structured CS databases (i.e., records collected in a systematic manner) provide important inputs for science (Jonzén, 2006). Furthermore, Nieto-Galan points out that, decades ago, Ludwick Fleck stressed that "scientists become experts through a long process of learning in which for years they have been students, laypeople, audiences and active agents in classroom culture, in the exchange of opinions between teachers and students" (Nieto-Galan, 2016, p. 118). Consequently, interaction is fundamental to understand the learning process and the sociocultural context where informal learning and the production of scientific knowledge take place. Fleck introduced the concept of Denkkollectiv (thought collective) to describe how scientific knowledge is produced under certain conditions of collective thought, often driven by reciprocity. He also introduced the concept of Denkstil (thought style), which describes a particular style of thinking (Fleck, 1935/1979). Fleck outlines his collective scientific thinking in four circles, where the two inner circles are known as esoteric and the two outer ones as exoteric. In the first inner circle, one finds a small group of research experts; in the second inner circle, one finds professionals. The third circle contains a large group of scientific laypeople, while the fourth and outermost circle contains the general public. Most importantly, Fleck conceives the operation of these circles as a system based on a democratic exchange:

The most characteristic operational feature is a democratic exchange of ideas and experience, going outward from the esoteric circle, permeating the exoteric circle, and then feeding back upon the esoteric circle. The work of the mind thus conveyed undergoes a process of social consolidation and becomes thereby a scientific fact. (Fleck, 1935/1979, p. 161)

Public participation in biodiversity mapping creates large amounts of data in a short time, and the concept of apomediation represents a new strategy of validation (Eysenbach, 2008). Apomediation is a socio-technological term used to describe the third way for users to identify trustworthy, credible information and services. Apo 
is derived from the Latin word for "stand by," and apomediation refers to the ability of Internet users-even those not considered experts-to bypass gatekeepers and intermediaries to go directly to sources when accessing information. In this way, the expert stands by the user.

Thus, democratic exchange is fundamentally concerned with understanding participation. Participation describes a) co-deciding on the technological infrastructure, b) co-deciding on the content, c) co-deciding with people following certain rules, and d) codeciding on or with organizational policy. Consequently, the aim in the present article is to ecologize participation and thus provide a relational co-productionist perspective on participation (Chilvers \& Kearnes, 2019; Hetland, 2017).

In the present study, access, interaction, and participation, as defined by Carpentier $(2012,2015)$, are used to study the bridging of contributory CS (e.g., the instrumentalist point of view) and democratized CS (e.g., the capacity-building point of view) and thereby also deal with how to handle controversial issues between different actors doing CS and between CS and professionalized science (Meyer, 2018).

\section{Method}

The study of biodiversity mapping presented here both utilizes semi-structured interviews with participants about CS access, interaction, and participation and the ethnography of online communities (Hetland \& Mørch, 2016)-studying dialogues on the SO web site and on Facebook-pages belonging to different groups of amateurs naturalists, to study how controversial issues, e.g. validation and collecting and preserving specimens, have been handled. Eight amateur naturalists and four professional biologists, one of them also representing public authorities, were selected for the interviews. As super users, all of the interviewees were acting as civic educators in collaboration with citizen communities. The eight amateur naturalists were recruited from three amateur societies: The Norwegian Entomological Society, the Norwegian Botanical Association, and the Norwegian Ornithological Society.?
The four professional biologists were: two from Sabima, one from the GBIF Norway, ${ }^{8}$ and one from the NBIC. The semi-structured interviews explored three main topics: 1) access, 2) interaction, and 3) participation. More detailed questions included their roles in CS activities, their activity over time, who they collaborated with, their CS communities, their training and experience in science, their motivation to partake in CS, and how the SO influenced CS activities. By including amateur naturalists, professional biologists, and public authorities partaking in the so, the present research results have greater credibility.

Table 1 provides an overview of activities and experience of the eight amateur naturalists who were selected for interviews.

\section{TABLE 1.}

\begin{tabular}{|c|c|c|c|c|c|c|c|c|}
\hline Interviewee number: & 1 & 2 & 3 & 4 & 5 & 6 & 7 & 8 \\
\hline Species-groups (10 possible at time of interview) & 1 & 9 & 9 & 9 & 5 & 9 & 7 & 3 \\
\hline Validator & Yes & No & No & Yes & No & Yes & Yes & Yes \\
\hline Engaged in collecting objects & Often & Seldom & Seldom & $\begin{array}{l}\text { Some- } \\
\text { times }\end{array}$ & Seldom & $\begin{array}{l}\text { Some- } \\
\text { times }\end{array}$ & Seldom & $\begin{array}{l}\text { Some- } \\
\text { times }\end{array}$ \\
\hline Experience collecting structured data & Yes & Yes & Yes & Yes & Yes & Yes & No & Yes \\
\hline
\end{tabular}

Table 1. Amateur Naturalist Interviewees

Table 1 specifies how many species-groups the amateur naturalists recorded, whether they themselves had been validators, whether they had collected physical objects, and whether they had experience with collecting structured data. At the time of the interviews the SO allowed records of the following 10 speciesgroups (as defined by them): vascular plants, mosses, lichens, fungi, invertebrates, birds, amphibians and reptiles, mammals (excluding bats), bats, and fish. (After these interviews were conducted an $17^{\text {th }}$ sub-species, algae, was added.) For the sake of anonymity, the details regarding which specific species were recorded by the participants and their exact numbers are not revealed here. However, information about the variety of species is included

7 The members of these three societies are among the most active on the SO portal (Hetland, 2020).

8 https://www.gbif.no/ 


\section{$\$$}

NORDIC JOURNAL

of Science and Technology Studies

(there are between one and nine species-groups). Five of the interviewees participate in validation. Fewer collect objects during the season-one does so often (several times per week), three sometimes (1-3 times per month), and four seldom (less than once per month). All except one have experience with collecting structured data, either because they have assisted professional teams or because they belong to a group of amateur naturalists that sometimes collect structured data.

The participants were selected with the help of the Sabima, which is very familiar with the number of amateur naturalists through validation activity. All of the selected amateur naturalists were super users of the SO. As an indicator of their activity, these participants have, on average, collected 1,575 different species and submitted 58,000 records each during the entire time they have been involved in the SO; this represents around $2.4 \%$ of the total records at the time of the interviews. The participants' educational levels were generally high. Both the contributors and their contributions have a heavy-tailed distribution (heavytailed distributions tend to have many outliers with very high values). The records in the database come from more than 12,000 contributors. At the "head" end, roughly $1 \%$ of the contributors have provided more than $40 \%$ of the records, while at the "tail" end, roughly $80 \%$ of the contributors have recorded approximately $1 \%$ of the records. All interviewees were among the "head" end. That participation can be very skewed is well known from other studies (Haklay, 2018), some even refer to the 9०-९-1 rule9 i.e. 9०\% or more contribute with almost nothing, $9 \%$ or more contribute infrequently or fairly little, while the last $1 \%$ contribute most of the information. Even if the SO has a heavy-tailed distribution, it is not as extreme as the 90-9-1 rule; the mid-group consists of $19 \%$ providing $59 \%$ of the records. One limitation of the study is that none of the many at the "long tail" were interviewed. Quite likely they would have been more involved in contributory CS and less in democratized CS. Furthermore, four of the eight amateur naturalists interviewed have training in science, from BSc level to PhD-level, two of them within the field in which they are involved as amateur naturalists. Consequently, the eight amateur naturalists selected represent extreme or deviant cases acting as civic educators. Extreme cases often reveal more information "because they activate more actors and more basic mechanisms in the situation studied" (Flyvbjerg, 2006, p. 229).

All of the semi-structured interviews were conducted over the phone by the author, since the participants were located in regions throughout Norway. They varied from 27-49 minutes in length, with an average interview lasting 37 minutes. All of the interviews were recorded by a dedicated voice recorder and transcribed by the author. The transcribed interviews were coded by the author with the help of the HyperRESEARCH software for computer-assisted qualitative data analysis. HyperRESEARCH allows the researcher to perform analytical induction on emergent code categories. HyperRESEARCH was selected because of user friendliness. Each interview was coded several times to test interpretations and facilitate a repeated comparison of the gathered data focusing on central elements, and picking out representative quotes (HesseBiber \& Dupuis, 2000).

\section{Findings}

The presentation of the results follows the AIP-model; results related to access are presented first. The results related to interaction and participation will then be presented.

Access is, according to Carpentier (2012, 2015), understood as presence (e.g. in an organizational structure or a community) related to four areas: technology, content, people, and organizations. More general data on access is presented above in Section 2. Previously, direct contact between the different museum curators and amateur naturalists was an important element for access, interaction, and participation. Now this direct contact is partly replaced by using the SO. The SO is frequently updated to ensure that all participants, including amateur naturalists, are behaving in as disciplined a manner as possible while also simultaneously including as many participants as possible. The amateur communities, as scientifically oriented groups, are rather skewed when it comes to interests in the different aspects of natural history. The skewing of biodiversity mapping is central to how we understand the world around us. When they were interviewed, the mappers had 10 different species-groups they could chose to map. Among these groups, bats had the fewest records and birds the most. Interestingly, the establishment of the so has slightly reduced the skewing of reported observations over time. However, skewing is still a crucial issue.

There are several reasons for skewing among amateur naturalists. When amateur communities in natural history form, it is reasonable to assume that skewing occurs in favor of the speciesgroups that individuals in the group are especially interested in. However, skewing may also be caused by how the amateur naturalists move across geographical areas and identify their favorite locations for observations. The majority of mappers have two or three favorite patches close to their home, vacation spots, or places where they go in their spare time.10 "When you look at a specific species on the Species Map, what you see is not necessarily

9 https://www.nngroup.com/articles/participation-inequality/

10 Approximately one half of all Norwegians have access to at least one cabin, while one third of all Norwegians have access to two or more cabins (Lien \& Abram, 2019). 
the geographic distribution of the species, but the geographic distribution of the observers" (Interviewee 6). However, skewing is not solely caused by favorite places or species; some species are simply avoided by mappers for a number of reasons: "I keep away from difficult species, for example, ants; they are so angry and more or less impossible to take a photo of" (Interviewee 3). In general, the so records unstructured data. However, there might also be structured data in the so from specific places, such as certain bird observatories. Of course, "If you collect on the same spot year after year, that is a kind of structure, and you will have a time series that might be interesting in biology" (Interviewee 6).

Interaction is, according to Carpentier (2012, 2015), understood as social-communicative relationships that are established with other humans or objects and related to four areas: technology, content, people, and organizations. The so offers its participants different resources to aid them in their recording activities. Several Facebook pages also appeared shortly after the establishment of the SO, and these are now used extensively to confirm the correct identification of specimens. Many people now ask for confirmation on these pages before they register a record in the so to ensure that they have made a correct identification. "It is no fun to get comments when you have identified the species incorrectly" (Interviewee 6). The fact that one species might have different Latin names for historical reasons also fosters a need for a species thesaurus and a standardized biological nomenclature. These synonym lists can change over time leading to frustration, as one user described: "When the Norwegian Biodiversity Information Centre changes names all the time, it is frustrating" (Interviewee 3).

Among the services that the SO offers its participants are ranking lists that cover several dimensions including the name of the observers, localities, and photos. These ranking lists are intended to encourage participation, but all of the amateur naturalists interviewed had a negative opinion of them. "I don't care about competition; I want to learn new species" (Interviewee 2). "There are a lot of trigger-happy people out there. They enter a lot of nonsensical information-garbage in, garbage out" (Interviewee 8). "Some people think it is more important to have their name attached to a rare species than to be sure it is correctly identified" (Interviewee 1). Thus, while it can be concluded that the group of amateur naturalists interviewed for this study think that the ranking lists put too much focus on competition, they also think that they encourage interaction.

Collecting specimens was once a crucial activity for amateur naturalists, as natural history research museums used to depend on them for obtaining material for their collections. Today, however, collection is not viewed with the same importance by amateur naturalists. First, photos have become a ubiquitous resource, and second, there is a growing reluctance to display dead animals which discourages potential collectors:
I am active on several Facebook groups where people ask for assistance identifying a given specimen. If you post a nice picture of a beautiful collected specimen, you will quickly get critical comments: "How are you able to kill such an innocent and beautiful creature?" I think people are reluctant to collect physical specimens since there are a lot of strong opinions about animal collectors; they don't understand the scientific value of collections. (Interviewee 6)

As several of the professional scientist state, the quality of the data erodes much faster when physical specimens are not available. Taxonomic work may suddenly split one species into three species, and, for that, pictures are of almost no value. Research museums, therefore, prefer physical specimens. Additionally, specimens are crucial for DNA analysis.

Opinions on collection also differ among those who collect. "Those who think they don't need the concrete specimen, that pictures are enough, have misunderstood. Anyhow, Red Listed insects are not threatened because of human collection, but by losing their habitats" (Interviewee 1). One participant noted that engaging in collection is important because, "It is not possible to decide correctly which insect it is without taking a specimen, doing DNA analysis, and comparing it with reference collections" (Interviewee 1). Furthermore, one participant claims to be "able to validate $85-90 \%$ by pictures; the rest, I need the actual specimen in hand" (Interviewee 6). Some still send their collected material to the natural history research museums, while others state that they "collect privately; however, I will donate my collection to the museum before I die" (Interviewee 1).

Amateur naturalists usually begin their activities at an early age. They don't necessarily follow a rigorous scientific method when recording: "I record in an arbitrary manner, just taking what I find" (Interviewee 3). However, several participants note a love of systems like the SO for several reasons: "I use [the] SO as my own field diary" (Interviewee 6). With the help of the Species Maps, the amateur naturalists can identify "white spots" to help fill in data. All of the interviewees stated that they do not keep their old field diaries. They use either the field diary option in the so or simply use the sO system as their field diary. These different versions of field diaries are important in their learning process: "I am very careful to document everything, and I am learning a lot through recording" (Interviewee 3). Some have also "digitalized a large amount of historical data" (Interviewee 4).

The interviewees have dual perspectives concerning validation: "I now comment on our Facebook group, but in the past, I emailed people since public comments might be experienced as a pillory" (Interviewee 5). In addition, the interviewees think that many of the SO participants, especially younger amateur naturalists, do not have all of the necessary skills: "Some are not able to read a map" (Interviewee 8). Documentation is also perceived as crucial: "I take 


\section{$\$$}

NORDIC JOURNAL

of Science and Technology Studies

photos the whole time and also through a microscope to document as thoroughly as possible. Some take the documentation more easily, then the value decreases" (Interviewee 3). Documentation is not only about correctly identifying the specimen but also about identifying its sex, geographic location, and activity. Understanding the significance of locality is especially important. "A Red Listed species might fly over a parking lot; however, it is not the parking lot that is valuable" (Interviewee 8).

An important cause of skewing can be both the observer's interest in rareness and the politics of knowledge, which give a certain priority to mapping rare species and invasive species. Of all the observations recorded so far in the SO, $15.5 \%$ are on the Red List, and $1.2 \%$ are on the Alien Species List. One interviewee commented that the SO is certainly an inspiration to "re-find rare species" (Interviewee 5). However, focusing on a rare species also leads to multiple records of the same specimen: "If a rare bird stays in the same place for a month, you might get hundreds of records of the same bird. It should be easier to just merge all those records into one" (Interviewee 8). Validation of a rare species can also be difficult: "If they have recorded one species that belongs to the Red List, I email them and ask for a picture. If they have no picture and no co-observer, I can't validate [it]" (Interviewee 1). Validation is not always a smooth process; "Sometimes, people are quarreling, more or less. I think SO should stop that" (Interviewee 3).

The Species Map Service ensures that information is available as soon as possible-the SO publishes first and validates thereafterbecause "The most important [thing] is that public authorities use the knowledge we provide" (Interviewee 5). Nonetheless, Sabima highlights that they work primarily with environmental authorities and much less with scientific organizations. Some of the interviewees state that the so should be more explicit about how the data are used, both today and in the future. In terms of how to make the SO more valuable by designing ways of structuring the data, several of the interviewees noted that an easy solution would be to follow specific localities in a more systematic way.

According to Carpentier $(2012,2015)$ participation is defined by power relations in decision-making processes related to four areas: technology, content, people and organizations. The general principles that the SO follows are presented above in Section 2. Some participants find the openness of the SO to be problematic because some species like the "hazel grouse that are very local" (Interviewee 4) might become vulnerable to hunting as a result. One interviewee does not "record golden eagles since they are vulnerable to being hunted by farmers" (Interviewee 8). Protecting information that relates to vulnerable species is legitimate. However, not everyone trusts that this is done in the right manner within the database.
Knowledge is temporary, which is why validation in the SO is a never-ending activity. This temporality is also emphasized by changes that move a lot of the activities within biodiversity mapping from the field to the laboratory. Floristic and faunistic knowledge is built on the morphological tradition stemming from, among others, Carl Linnaeus (1707-1778), while twentieth-century science is strongly linked to the molecular tradition that uses DNA and similar forms of new knowledge. Amateur naturalists are still mostly dependent on morphology, while professional scientists work with new technologies and methods, potentially weakening knowledge about the ecological contexts that accompany traditional methods.

Validation activity was a topic that was most frequently discussed by the amateur naturalist interviewees, and it was also the activity that provoked the strongest feelings. A certain shared belief exists that "In the SO, they overlook the human factor; they try to do with machinery what usually is best done by man" (Interviewee 8). The validators are often recruited from among the most skilled amateur naturalists. All of the interviewees who participated in validation made statements such as: "The only way to professionalize validation is to pay the validators-to validate all in my group would have been a full-time job" (Interviewee 6). It's OK that people contribute their own observations voluntarily; however, validation is a job.

As noted, five of the eight interviewees participate in validation activity, and all eight of the interviewees have experience with validation in one way or another. They had many thoughts concerning validation: "Some think that it is better to have a large volume than to ensure it is absolutely correct" (Interviewee 5). "It is not possible to validate in a cost-efficient manner" (Interviewee 8). "In the old system [before 2015], we [validators] had the authority to correct the wrong information. Now you have to enter into a dialogue with the observer. It is really time consuming" (Interviewee 8). One example of the time-consuming nature involves the validation of an observation of a species on the Red List, where the validators "expect documentation, like description from a competent observer, photos, sound files, or biological material" (Interviewee 8). If such information is lacking, the validator might ask for it, and "If they don't have a picture and have not communicated with an expert, then I can't validate [the observation]" (Interviewee 1). According to the NBIC, there is no reason to believe that the quality of the data in the SO is lower than that of the databases of professional research institutions. All the validators mentioned examples of "hopeless people" who mess around and should be stopped, but they find this to be difficult. While people do receive certain restrictions, they are seldom expelled. According to the NBIC, fewer than 10 users have misused the system, and they are in the process of excluding one misuser after a long process."

11 Please see https://www.artsobservasjoner.no/Home/DeviatingReports 


\section{Discussion}

First of all, the present study focuses on super users to study the co-construction processes. The aim is not to conclude that all individual participants partake on all three levels within the AIP model, but that the participants as a group do so. As mentioned earlier, a study of access, interaction, and participation was conducted to attempt to answer the following research question: How do civic educators and citizen communities in a large CS project co-construct access, interaction, and participation and bridge contributory and democratized CS? The main aim with this article is theory building by studying the usability of the AIP model within CS studies. In this section, I discuss how access, interaction, and participation are co-constructed.

Access is a crucial condition for the possibility of interaction and participation. Consequently, all CS activities has access as the first foundation stone facilitating presence. However, access may be achieved in many different ways, either by bottom-up processes involving a large group of actors-including amateur naturalists and their organizations-or by top-down processes where the experts designs a relevant system. In building the SO, amateur naturalists and their societies, together with scientists and public authorities, have acted as strategists, formed alliances, mobilized resources, and built a technological infrastructure (Bowker, 2000; Bowker \& Star, 1999; Karasti et al., 2016a, 2016b) for contributory CS. Access through well-functioning technology is a precondition for joining the ranks of records, contributors, validators, and institutional actors. NGOs like the amateur organizations, including Sabima, public authorities like the NBIC, and scientific institutions like natural history museums and the GBIF take on the role of civic educators developing and implementing educational resources. The recent work is part of a long history where uncredentialed naturalists have made greater contributions to science than many academic biologists (Kohler, 2006). Natural history research museums and their collections are now enjoying a second, molecular scientific life supported by this long history.

Furthermore, the development of interesting content is necessary to maintain the interests of all relevant actors, be it amateur naturalists and their societies, public authorities that are paying for the maintenance of the system and using the results, or scientific research that benefits from large-scale biodiversity mapping activity. One important aim is to motivate as many people as possible to participate to avoid skewing in data collection. The participants are able to access the content in a growing number of ways, facilitating both individual projects following the individual amateur naturalist's own interests and nationwide projects of national interests. Two important consequences of all the mentioned activities is first that the participants experience how amateur naturalists' contributions matter through building a database that facilitates a number of new services of national importance, and, second, how civic education in the form of capacity-building improves the participants as a group. As a group they take on the role of both expert and advocate.

Co-construction took place among organizations like the amateur societies who argued strongly for a service like the so (using the Swedish Artsportalen as their exemplar) and convinced the public authorities that such an infrastructure would be mutually beneficial. Hence, to secure stability and innovation, it was important to secure long-term funding by enrolling public authorities. At the same time, the contextual circumstances were favorable, and biodiversity concerns were placed on the agenda by a heterogeneous group of actors. By facilitating co-construction as an ongoing process, one also avoids one crucial pitfall of many participatory projects: that what is co-constructed may end up as transient CS activities that are dissolved as soon as the interest (and/or money) of the initiators end.

Interaction is the second cornerstone of participation, and interaction implies some degrees of reciprocity (Carpentier, 2015). Over time the technology opens up for a growing number of species groups, and the SO may be used to plan recording activities identifying unmapped places or "white spots." The primary content added to the platform may also be used to produce secondary content like private diaries, ranking lists, maps, etc. The movement in science from the field to the laboratory widens the gap between professional scientists and amateur naturalists. Nonetheless, amateur naturalists continue to contribute much local knowledge. The hierarchal structure of professional scientists and amateur naturalists is also different. Professional scientists consider being a respected researcher within her discipline to be important, while amateur naturalists consider being a respected amateur naturalist as important and have limited tolerance for ignorance within biodiversity mapping. Furthermore, the individual knowledge strategies of the amateur naturalists emphasize local patches and favorite species-groups (Conniff, 2011). However, over time the establishment of the SO has slightly reduced the skewing of reported observations. One important reason for this is quite likely the mobilization of a large number of amateur naturalists and that the digital infrastructure of the so has improved transparency. Another reason is the move from emphasizing dyadic person-to-person dialogues to emphasizing polyadic dialogues on social media. These polyadic dialogues also imply a shared ontological commitment that distinguishes the participants as a broad citizen-science community of practice (Ceccaroni et al., 2017). From the interviews we know that the shared ontological commitment within the two inner esoteric circles of Fleck are drawn from the language of science, while the two outer exoteric circles are drawn from everyday language. However, a growing number of highly skilled amateur naturalists are able to move between the two worlds, partaking both in a broad citizen-science community of practice and in a narrower scientific community. 
Sahlins (1972) uses the reciprocity concept to develop an understanding of the domestic mode of production, even if market relations also contain crucial elements of reciprocity. Among the validators, there is a general claim that contributing one's own records and validating the records of others are very distinct enterprises, especially since validators also take on a crucial educational role, being in the frontline of knowledge mobilization. When one is contributing one's own records it is fun and interesting, and it is quite all right that the work is voluntary. However, it is important that the contributions are taken seriously and reciprocated (Harris, Wyatt, \& Kelly, 2013). Examples of such reciprocation include digital diaries, resources to aid recording activities, ranking lists (even if they are much debated), learning opportunities, new collection strategies, and a system of validation. All of these examples have a high personal relevance (Frewer et al., 1999) that improve the quality of biodiversity mapping. When validating the records of others, one is doing a necessary job for the community. According to the interviewees, it is somewhat boring in the long run and takes time away from doing what they like the most. Consequently, the activity should be looked upon as a traditional market relationship-it is a job for which one should be paid. Thus, while the so reciprocates to the amateur naturalists in a highly relevant manner, it does not do so for its validators.

Balanced or symmetrical reciprocity is the most apparent version of reciprocity when studying biodiversity mapping. On average, each of the interviewees collected 1,575 different species and submitted 58,000 records. Generally, such work is not done solely for the common good. More often it is done for personal reasons-such as instilling order among their own observations or making use of the SO as their own field diary-which in turn makes them visible to the community of fellow amateur naturalists and helps them achieve status as a knowledgeable and experienced amateur naturalist. Consequently, reciprocity also facilitates long term engagement. Personal relevance here is crucial. This knowledge may be useful in assisting others in validation work. The so practices a form of openness that is sometimes experienced as problematic and, consequently, several Facebook pages have appeared facilitating apomediation (Eysenbach, 2008). The main purpose of the Facebook pages is to establish an arena for communication and learning which participants experience as informal and comfortable, as promoting a respectful atmosphere is important for facilitating opportunities for reciprocity (Kramer \& Wells, 2005).

Sahlins (1972) also explored the concept of negative reciprocity, which is characterized by the attempt to get something for nothing. Many of the interviewees concerned with negative reciprocity think of it as a form of theft. According to the interviewees, some harvest data from the SO for their own gain, unconcerned about giving something back. One example of this is the illegal hunting of protected species. (Such hunting sometimes becomes legal, however, since public authorities allow their hunting if a protected species attacks domestic animals or appears outside of their zone of protection.)

Organizations are crucial to maintaining the general principles that the SO has established. "Unskilled" amateur naturalists or "hopeless people," according to several of the interviewees, do not contribute, and several of the interviewees desire an easier way of expelling them. However, expelling participants violates the most important general principle guiding the SO, which is that everyone may contribute, regardless of their skills. Consequently, it is sometimes difficult to maintain a comfortable and respectful atmosphere within the SO, and this frustrates some of the participants (Kramer \& Wells, 2005). However, controversies are also an important part of science, be it among professionals or amateur naturalists (Meyer, 2018). The heterogeneity that Secord (1994) finds among amateur naturalists is still there, even if the class aspect is downplayed; skills are currently growing in importance. In this respect, one finds circles of interaction similar to those Fleck describes (1935/1979). The establishment of the SO has increased a large group of participants' knowledge of complex modern problems and how these problems may be addressed through science and policy like e.g. the Red List and the Alien Species List. Furthermore, participation quite likely contributes to an increased understanding of how science changes over time as the participants experience these changes, e.g., how the synonym lists change over time. The interviews also made apparent that the advocate role is of great significance to civic educators (Ceccaroni et al., 2017).

Access and interaction "within a participatory process are necessary requirements for the participatory process to exist" (Carpentier, 2015, p. 24). While access and interaction signify contributory CS, participation signifies democratized CS. Democratized CS is not better than contributory CS, but democratized CS adds the study of power to CS (Irwin, 1995). Most amateur naturalist only contribute; they do not participate in co-deciding. However, the study of CS needs to include power as a crucial dimension, even if power is only openly played out at an organizational level among representatives. The choice of technology involves important dimensions of power, as technology structures actions. Consequently, new versions of the system is not only to modernize the technological infrastructure (Bowker, 2000; Bowker \& Star, 1999; Karasti et al., 2016a, 2016b), but also to enhance user experience. Most amateur naturalists understand that they are partaking in a huge communal undertaking producing new content and that the value of their contribution is quantifiable, as they can provide a map of Norwegian biodiversity both across time and space. However, the quality of this map rests on their ability to avoid skewing and collect well-validated data. The difference between participants is primarily a question of different collection strategies and validation methods. Both professional scientist and amateur naturalists emphasize that knowledge should be correct and validated. However, the methods for collecting unstructured 
and structured data are quite different. One reason for this not being an overly problematic situation is the difference in goals between the scientists and amateur naturalists. While scientists aim to provide something of scientific value to biodiversity, most amateur naturalists are more concerned with environmental citizenship. Simply put, their Denkstil (Fleck, 1935/1979)-their particular style of thinking-may be different. However, their ability to help build and sustain the infrastructure also illustrates that participation is organizational power, enacted both from the bottom-up and top-down. The inclusive style of participation and co-production also underlines important democratic traditions. Organizations are crucial when it comes to democratized CS. They link practitioners, stimulate innovation, address common challenges, and, together with professional biologists and public authorities, they develop shared ontological commitment, norms, and standards. This work increases the visibility of citizen-science community of practice to society at large. From more quantitative studies we also know that many participants appreciate the advocate role, even if they don't perform this role within the citizen-science community of practice (Hetland, 2020). Finally, co-deciding is not only performed within the citizen-science community of practice; it is, even more importantly, part of democratic engagement in the larger society. As Kohler (2006) underlines, biodiversity is a lively issue, mainly because of the number of species that are going extinct, and the different NGOs stemming from the amateur communities also work to place biodiversity on the political agenda.

\section{Conclusion}

Civic educators in the form of leading amateur naturalists, scientists and public authorities work together with citizen communities to advance biodiversity mapping, foster a broad scientific mentality, and encourage democratic engagement. This allows society to deal rationally with complex modern problems like loss of biodiversity both across time and space. The AIP model has strong analytical capacities, providing a framework for understanding the rather vague concept of participation in a more systematic manner that differentiates between access, interaction, and participation. Access is grounded in well-functioning technological infrastructures like the Species Observations System, interaction is promoted by civic educators that foster a broad understanding of biodiversity mapping, and, finally, participation is encouraged by organizations that aim to deal rationally with complex modern problems like loss of biodiversity. As a crucial theoretical contribution, the AIP model ecologizes the study of CS, building bridges between contributory CS (e.g., the instrumentalist point of view) and democratized CS (e.g., the capacity-building point of view). This bridge-building increases the relevance of both models of CS to society at large and secures resources for a long-lasting activity.

\section{Acknowledgements}

The author thanks the participants in the study for sharing their experiences and the reviewers for helpful comments. The study is made possible by grant 247611 from The Research Council of Norway and before going into the field, I obtained ethical clearance from the Norwegian Social Science Data Services (NSD). The author declares that there is no conflict of interest.

\section{References}

Batson, C. D., Ahmad, N., \& Tsang, J. A. (2002). Four motives for community involvement. Journal of social issues, 58(3), 429-445. https://doi.org/10.1171/1540-4560.00269

Bonney, R. (1996). Citizen Science: A Lab Tradition. Living Bird 15(4), 7-15.

Bonney, R., H. Ballard, R., Jordan, E., McCallie, Phillips, T., Shirk, J., \& Wildermam, C. (2009). Public participation in scientific research: Defining the field and assessing its potential for informal science education. Centre for Advancement of Informal Science Education (CAISE).

https://www.informalscience.org/sites/default/files/Public ParticipationinScientificResearch.pdf

Bonney, R., Philips, T. B., Ballard, H. L. \& Enck, J. W. (2016) Can citizen science enhance public understanding of science? Public Understanding of Science 25(1), 2-16.

https://journals.sagepub.com/doi/10.1177/0963662515607406
Bowker, G. C. (2000). Biodiversity datadiversity. Social studies of science, 30(5), 643-683. https://doi.org/10.1177/030631200030005001

Bowker, G., \& Star, S. L. (1999). Sorting things out: Classification and its concequences. The MIT Press.

Carpentier, N. (2012). The concept of participation. If they have access and interact, do they really participate? Communication Management Quarterly 14(2),164-177.

https://doi.org/10.4013/fem.2012.142.10

Carpentier, N. (2015). Differentiating between access, interaction and participation. Conjunctions: Transdisciplinary Journal of Cultural Participation 2(2),7-28. https://doi.org/10.7146/tjcp.v2i2.23117

Carrier, J. (1991). "Gifts, commodities, and social relations: A Maussian view of exchange. Sociological Forum 6(1), 119-136. https://doi.org/10.1007/BFo1112730 
Cavalier, D., \& Kennedy, E. B., (Eds). (2016). The rightful place of science: Citizen science. Consortium for Science, Policy \& Outcomes.

Ceccaroni, L., Bowker, G. \& Brenton, P. (2017). Civic education and citizen science: Definitions, categories, knowledge representations." In L. Ceccaroni and J. Piera (Eds.) Analyzing the Role of Citizen Science in Modern Research (pp. 1-23). IGI Global.

Chilvers, J., \& Kearnes, M. (2019). Remaking participation in science and democracy. Science, Technology \& Human Values 44(4), 1-34. https://doi.org/10.1177/0162243919850885

Conniff, R. (2011). The species seekers: Heroes, fools, and the mad pursuit of life on earth. W. W. Norton \& Co.

Eysenbach, G. (2008). Medicine 2.0: Social networking, collaboration, participation, apomediation, and openness. Journal of Medical Internet Research 10(3), 1-9.

https://doi.org/10.2196/jmir.1030

Fleck, L. (1979). Genesis and development of a scientific fact (F. Bradley \& T. Trenn Trans.) University of Chicago Press. (Original work published 1935).

Flyvbjerg, B. (2006). Five misunderstandings about case-study research." Qualitative Inquiry 12(2), 219-245.

https://doi.org/10.1177/1077800405284363

Frewer, L. J., Howard, C., Hedderley, D., \& Shepherd, R. (1999). Reactions to information about genetic engineering: Impact of source characteristics, perceived personal relevance, and persuasiveness." Public Understanding of Science 8(1), 35-50. https://doi.org/10.1088/0963-6625/8/1/003

Haklay, M. (2018). Participatory citizen science. In S. Hecker, M. Haklay, A. Bowser, Z. Makuch, J. Vogel, \& A. Bonn (Eds.) Citizen science: Innovation in open science, society and policy, (pp. 52-62). UCL Press.

Harris, A., Wyatt, S., \& Kelly, S. E. (2013). The gift of spit (and the obligation to return it): How consumers of online genetic testing services participate in research. Information, Communication \& Society $76(2), 236-257$.

https://doi.org/10.1080/1369118X.2012.701656

Hecker, S., Haklay, M., Bowser, A., Makuch, Z., Vogel, J., \& Bonn, A. (Eds.) Citizen science: Innovation in open science, society and policy. UCL Press.

Hesse-Biber, S., \& Dupuis., P. (2000). Testing hypotheses on qualitative data: The use of HyperResearch computer-assisted software." Social Science Computer Review 18(3), 320-328. https:// doi.org/10.1177/089443930001800307

Hetland, P. (2011). Science 2.0: bridging science and the public. Nordic Journal of Digital Literacy, 6(Special Issue), 326-340.

Hetland, P. 2017. Rethinking the social contract between science and society: Steps to an ecology of science communication. Dr.philos.thesis, Department of Education, University of Oslo.

http://urn.nb.no/URN:NBN:no-58370

Hetland, P. (2019). Constructing publics in museums' science communication. Public Understanding of Science, 28(8), 958-972. https://doi.org/10.1177/0963662519870692
Hetland, P. 2020. The Quest for Reciprocity: Citizen science as a form of gift exchange. In P. Hetland, P. Pierroux \& L. Esborg (Eds.) A History of Participation in Museums and Archives: Traversing Citizen Science and Citizen Humanities (pp.257-277) Routledge.

Hetland, P., \& Mørch, A. I. (2016, November). Ethnography for investigating the Internet. In Seminar. net 12(1).

https://journals.hioa.no/index.php/seminar/article/view/2335

Hetland, P., \& Schrøder, K. C. (2020). The Participatory Turn: Users, Publics, and Audiences. pp. 168-185. In P. Hetland, P. Pierroux \& L. Esborg (Eds.) A History of Participation in Museums and Archives: Traversing Citizen Science and Citizen Humanities (pp. 168-185) Routledge.

Irwin, A. (1995). Citizen science: A study of people, expertise and sustainable development. Routledge.

Jardine, N., Secord, J. A., \& Spary, E. C. (Eds.) (1996). Cultures of natural history. Cambridge University Press.

Jennett, C., Furniss, D., Iacovides, I., Wiseman, S., Gould, S. J. J., \& Cox, A. L. (2014). Exploring citizen psych-science and the motivations of errordiary volunteers. Human Computation 1(2), 201-220. https://hcjournal.org/index.php/jhc/article/view/18

Jonzén, N., Lindén, A., Ergon, T., Knudsen, E., Vik, J. O., Rubolini, D., Piacentini, D., Brinch, C., Spina, F., Karlsson, L., Stervander, M., Andersson, A., Waldenström, J., Lehikoinen, A., Edvardsen, E., Solvang, R., \& Stenseth, N. C. (2006). Rapid advance of spring arrival dates in long-distance migratory birds. Science, 372(5782), 1959-1961. https://doi.org/10.1126/science.1126119

Kamp, J., Oppel, S., Heldbjerg, H., Nyegaard, T., \& Donald, P. F. (2016). Unstructured citizen science data fail to detect long-term population declines of common birds in Denmark. Diversity and Distributions, 22(10), 1024-1035.

https://doi.org/10.1777/ddi.12463

Karasti, H., Millerand, F., Hine, C. M., \& Bowker, G. C. (2016a). Knowledge infrastructures: Part I. Science \& Technology Studies 29(1), 2-12.

Karasti, H., Millerand, F., Hine, C. M., \& Bowker, G. C. (2016b). Knowledge infrastructures: Part II. Science \& Technology Studies 29(2), 2-6.

Kohler, R. E. (2002). Landscapes and labscapes: Exploring the lab-field border in biology. The University of Chicago Press.

Kohler, R. E. (2006). All creatures: Naturalists, collectors, and biodiversity, 1850-1950. Princeton University Press.

Kramer, D. M., \&Wells, R. P. (2005). Achieving buy-in: building networks to facilitate knowledge transfer. Science Communication, 26(4), 428-444. https://doi.org/10.1177/1075547005275427

Land-Zandstra, A. M., Devilee, J. L., Snik, F., Buurmeijer, F., \& van den Broek, J. M. (2016). Citizen science on a smartphone: Participants' motivations and learning. Public Understanding of Science, 25(7), 45-6o.

https://doi.org/10.1177/0963662515602406

Lien, M. E., \& Abram, S. (2019). Hytta: Fire vegger rundt en drøm. Kagge. Mauss, M. (2002). The Gift: The form and reason for exchange in archaic societies (W. D. Halls, Trans.) Routledge. (Original work published 
1950)

Meyer, G. (2018). The science communication challenge: Truth and disagreement in democratic knowledge societies. Anthem Press.

Nieto-Galan, A. (2016). Science in the public sphere: A history of lay knowledge and expertise. Routledge.

Rowe, G., \& Frewer, L. J. (2005). A typology of public engagement mechanisms. Science, Technology, \& Human Values, 30(2), 251-290. https://doi.org/10.1177/0162243904271724

Sahlins, M. (1972). Stone-Age economics. Aldine de Gruyter.

Secord, A. (1994). Science in the pub: artisan botanists in early nineteenth-century Lancashire. History of science, 32(3), 269-315. https://doi.org/10.1177/007327539403200302

Sherry Jr, J. F. (1983). Gift giving in anthropological perspective. Journal of consumer research, 10(2), 157-168.

https://doi.org/10.1086/208956
Shirk, J. L., Ballard, H. L., Wilderman, C. C., Phillips, T., Wiggins, A., Jordan, R., McCallie, E., Minarchek, M., Lewenstein, B. V., Kransky, M. E., \& Bonney, R. (2012). Public participation in scientific research: a framework for deliberate design. Ecology and society, 17(2). http://dx.doi.org/10.5757/ES-04705-170220

West, S. E., \& Pateman, R. M. (2016). Recruiting and retaining participants in citizen science: What can be learned from the volunteering literature?. Citizen Science: Theory and Practice. 2(1), 1-10.

https://doi.org/10.5334/cstp.8

Woolley, J. P., McGowan, M. L., Teare, H. J., Coathup, V., Fishman, J. R., Settersten, R. A., ... \& Juengst, E. T. (2016). Citizen science or scientific citizenship? Disentangling the uses of public engagement rhetoric in national research initiatives. BMC medical ethics, 17(1), 33 .

https://doi.org/10.1186/s12910-016-0117-1 